\title{
MORPHOLOGY OF WOOD SPECIES AFFECTING WOOD-THERMOPLASTIC INTERACTION: MICROSTRUCTURE AND MECHANICAL ADHESION
}

William Gacitúa ${ }^{1}$, Michael Wolcott ${ }^{2}$

\begin{abstract}
The main objective of the research presented here was to relate anatomical features of wood species that affect the interactions between polymeric phases and performance of wood plastic composites (WPC). These interactions were related to the probable interlocking volume and surface area for stress transfer in a WPC. Composites were produced from different wood species and analyzed using SEM (scanning electron microscopy). Results showed that wood species with high interfacial areas may increase mechanical interlocking, reflected in the viscous constant of the Maxwell model. A complicating factor was that the relation of cell wall thickness-lumen diameter and the interconnectivity between wood cells in a wood, affect the potential for cell collapse. When wood cells collapse, the penetration of the thermoplastic into the wood structure was almost always ceased. The collapse of wood cells during extrusion-injection molding processes reduced the potential surface for stress transfer between phases affecting the mechanical properties of composites. Undamaged wood cells may potentially be filled with HDPE thermoplastic enhancing modulus and increase the strength of WPC.
\end{abstract}

Keywords: Wood species, wood plastic composites, mechanical interlocking, viscoelastic model.

\section{INTRODUCTION}

The study of wood plastic composites is an emerging area in materials science. Wood as a natural filler is low-cost material with low density and high specific properties, and is also biodegradable and non-abrasive. Stark (1997) studied whether the wood species influences the mechanical properties of WPCs and investigated the micro-structural interactions between the wood and HDPE. According to Wolcott (2003), SEM micrographs of Southern yellow pine (Pinus spp.) composites revealed that the thermoplastic penetrates the pits around the periphery of the wood particles. In contrast, micrographs of a Douglas-fir composite (Pseudotsuga menziesii) did not reveal such penetration.

Pore penetration and roughness may seriously affect the extent of contact between the matrix and filler phases in a composite (Packman 2003). Surface roughness may range in scale from hundreds of microns to nanometers. Packman (2003) found that increasing the surface area between phases increases the measured surface energy per unit nominal area. Also, surface area and contact between phases may interact to redistribute stress and thus increase energy dissipation between a filler and matrix during the failure of composites. To examine the effects of different wood species, composites were made using wood flour from ponderosa pine, loblolly pine, maple and oak as filler for polypropylene at 20, 30, 40, 50 , and $60 \%$ by weight (Stark 1997). Results showed that with increasing wood flour content, the flexural and tensile modulus, density, heat deflection temperature, and notched impact energy increased, while the flexural and tensile strength, tensile elongation, mold shrinkage, melt flow index, and un-notched impact energy decreased. Hardwoods exhibited slightly higher heat deflection, as well as tensile and flexural properties than softwoods.

\footnotetext{
${ }^{1}$ Assistant Professor, Dpto. Ingeniería en Maderas, Facultad de Ingeniería, Universidad del Bio-Bio, Concepción, CHILE.

${ }^{2}$ Professor and Research Director, Wood Materials \& Engineering Laboratory, Washington State University, Pullman WA, USA 
Creep, the deformation over time of a material under stress, is one characteristic correlated to interface adhesion in composites. Increasing the amount of filler in a composite enhances creep resistance. Some researchers have used a creep test to describe strain behavior and interfacial interactions (Nunez et al. 2004, Houshyar et al. 2005, Acha et al. 2007). Houshyar et al. 2005 used a four-parameter viscoelastic model to quantify the viscoelastic behavior of polypropylene fibers reinforced composites. They found high agreement between creep model predictions and experiment results from high interfacial bonding between the fiber and matrix. They also studied the morphology of the composites using optical and scanning electron microscopy. SEM photographs displayed a thin layer of matrix on the reinforcement, which was attributed to good impregnation and wetting of the fibers to the matrix, enhancing the adhesion between phases. According to Acha et al. (2007), creep deformation could be directly related to interfacial properties, and this effect is enhanced when compatibilizers like maleated polypropylene are used.

Due to the production parameters of composites, they commonly contain large numbers of inhomogeneities such as cracks, voids, matrix pockets, and fiber bundle misalignments. These features cause an appreciable scatter in strength which is higher than for conventional materials. In the design process for composites, one must use statistical tools to adjust for this variability in properties (OmenaPina et al. 2004). The Weibull distribution is one of the most widely used statistical tools for materials such as composites. Omena-Pina et al. (2004) found that the Weibull modulus was useful for describing the flaw population of bi-directional carbon fiber reinforced carbon composites. It is possible that in the complex interactions between wood particles and thermoplastics in WPC, the mechanical interlocking between the natural filler and thermoplastics are significantly affected by the anatomical features of wood species. The goal of this research is to establish relationships between the anatomical features of wood, and microstructure, mechanical adhesion and performance of softwood WPCs.

\section{MATERIALS AND METHOD}

Five solid wood sections, measuring $5 \times 5 \mathrm{~cm}^{2}$ in cross section, were obtained from the inner area (close to the pith or corewood) and outer area (close to the bark or outerwood) of logs obtained from forests in the Inland Northwest region and for the following species: Lodgepole pine (Pinus contorta Dougl), Grand fir (Abies grandis) and Douglas-fir (Pseudotsuga menziesii). This material was subsequently reduced to wood flour using a Bliss hammer mill, dried to a nominal moisture content of $2 \%$ and screened to obtain a 60-mesh fraction for composites manufacture. Pellets of HDPE (LB 0100-00, melt flow index $\mathrm{MFI}=0.3 \mathrm{~g} / 10 \mathrm{~min}$ ), were used for the extrusion trial and for the injection molding.

Extrusion and injection: A Leistritz ZSE $18 \mathrm{HP}, 18 \mathrm{~mm}$ twin screw extruder was used for compounding. Wood flour-HDPE composites of $40 \%$ wood by weight were made without additives. The screw speed, barrel temperature and melt pressure at the die were $70 \mathrm{rpm}, 180^{\circ} \mathrm{C}$ and 3450 to $3800 \mathrm{kPa}$ respectively. A round orifice die was used in the extruder to produce the composite for the subsequent pelletization. The produced pellets were used to feed the Sumitomo SE 50D injection molder. Injection molding trials for each combination wood species-location were run, while processing conditions were held such that mold filling occurred in 2 seconds with a cooling time about 25 seconds. During plasticization, the screw speed was set at $200 \mathrm{rpm}$ and rear-to-front (hopper to nozzle) temperature profile was regulated to 185 ${ }^{\circ} \mathrm{C}$. The filling pressure and mold temperature were $1100 \mathrm{~kg} / \mathrm{s}$ and $70{ }^{\circ} \mathrm{C}$ respectively. The mold allowed one tensile bar and one flexure bar per cycle for mechanical testing, according ASTM D638 and ASTM D790. Type I tensile specimens and $12 \times 3 \times 127 \mathrm{~mm}$ flexure bars were produced. 
Macroscopic features of wood species: The latewood and earlywood proportion of representative wood samples was quantified by analyzing thirty square sections from the $5 \times 5 \mathrm{~cm}^{2}$ sections for each combination of wood species and location. The cross-section of the square sections were scanned with a HP Scanjet ADF scanner. The digitized images were analyzed using Image-pro software. To determine the latewood proportion on each image (area based), a bi-level mask (sensitivity $=4$ ) was used to manually select the intensity range of latewood. Once selected, the latewood proportion $\left(l_{w}\right)$ was determined based on the fraction of total scanned area $\left(25 \mathrm{~cm}^{2}\right)$. The earlywood proportion $\left(e_{w}\right)$ was then calculated as: $\quad e_{w}=1-l_{w}$

Phase morphology: Five flexure samples were selected from injection molding composites made with flour representing the combination of wood species and locations. Small $6.0 \times 2.8 \mathrm{~mm}^{2}$ cross areas were sectioned, which represents half of the cross section of a flexure injection sample. The sample surface was polished with a diamond knife mounted in a Leica ultramicrotome. Assuming symmetric morphology, both sides of the midline on this cross section (Figure 1) have similar microstructure. Four areas of interest (AOIs) of $770 \times 880 \mu \mathrm{m}^{2}$ were obtained using a Hitachi S-570 scanning electron microscope (SEM) with a magnification of up to $120 \mathrm{x}$, voltage $20 \mathrm{kV}$ and work distance $20 \mathrm{~mm}$. A total of $20 \mathrm{AOIs}$ per combination wood species-location were analyzed. SEM pictures were digitized and then processed. These pictures were used to analyze the morphology of wood particles embedded in the HDPE matrix. Cell collapse and interpenetration of HDPE into the filler was observed. The SEM analysis allowed an important feature to be found and measured: the void content. This is the percentage of void area per AOI, and was measured using image analysis through a pruning filter with a threshold number of 53 .

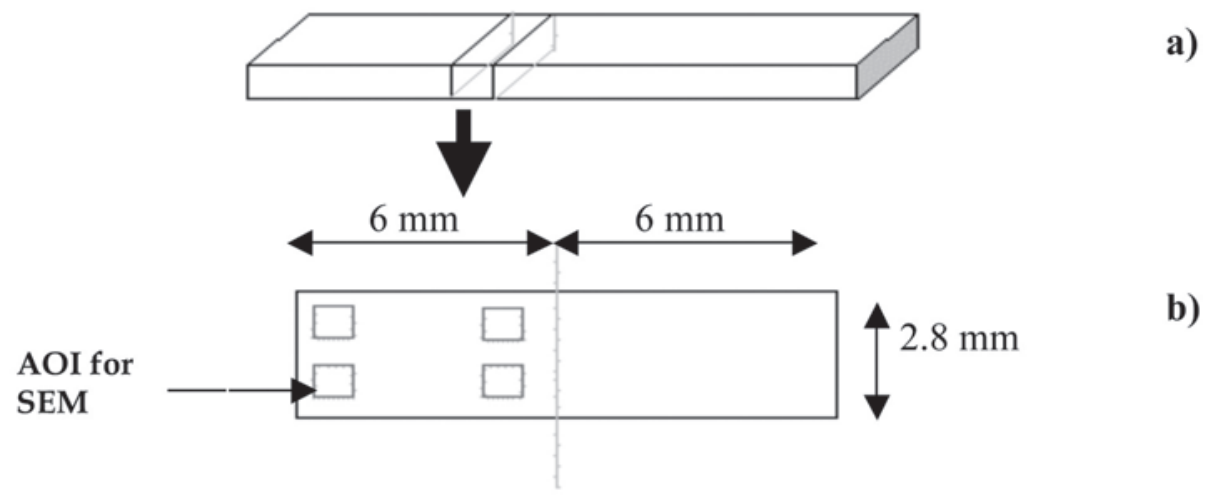

Figure 1: Flexure injection sample (a) and AOIs on the cross section (b) for SEM analysis and void content determination.

Viscoelastic parameters and mechanical adhesion in WPC. Small specimens $\left(2.8 \times 12 \times 60 \mathrm{~mm}^{3}\right)$ were cut from the injection molded flexure specimens and used for a creep test in a Rheometrics RSA II dynamic mechanic analyzer. Creep tests were conducted with a three-point flexure system using 7850 $\mathrm{mN}$ static load in an environment at $60^{\circ} \mathrm{C}$. A total test time of 10-min at constant load was used for all cases. A four-element Maxwell-Voigt Kelvin model, shown in Figure 2, was used to fit to the data for determining the viscoelastic parameters for WPCs; the procedure for determining the model parameters is based on the procedure described by Throne (1988). The four parameter model qualitatively accounts for the observed response of WPC under constant load; it includes instantaneous elastic strain, retarded elastic strain and viscous flow. This model results from the combination of the Maxwell and Voigt elements. For the four parameter model, the total deformation is:

$$
\varepsilon_{\mathrm{T}}=\varepsilon_{\mathrm{M}}+\varepsilon_{\mathrm{V}}
$$


where $\varepsilon_{\mathrm{M}}$ and $\varepsilon_{\mathrm{V}}$ are the strain of the Maxwell and Voigt elements respectively (Throne 1998). The governing differential equations for these elements are

$$
\begin{gathered}
\text { Maxwell: } \dot{\sigma}+\left(\frac{E}{\eta}\right) \sigma=E \dot{\varepsilon}_{M} \\
\text { Voigt: } \dot{\varepsilon}+\left(\frac{E}{\eta}\right) \dot{\varepsilon}_{v}=\frac{\sigma}{\eta}
\end{gathered}
$$

where $\dot{\sigma}$ and $\dot{\varepsilon}$ are the first time derivatives of stress and strain; respectively. Subscript ${ }_{\mathrm{M}}$ and $_{\mathrm{V}}$ denote the Maxwell and Voigt, respectively), $\sigma$ is the applied constant stress, and $E$ and $\eta$ are the elastic and viscous constants for the spring and dashpot for each model. By combining equation 2 and 3 , the final model provides responses to constant stress, strain rate and instantaneous fixed strain; then the response of the 4-parameter model is:

$$
\varepsilon=\left[\frac{\sigma_{0}}{E_{1}}+\frac{\sigma_{0} t}{\eta_{1}}\right]+\frac{\sigma_{o}}{E_{2}}\left(1-e^{-\left(\frac{E_{2} t}{\eta_{2}}\right)}\right)
$$

where, $\sigma_{\mathrm{o}}$ is the applied stress $(5,630 \mathrm{kPa})$, $\mathrm{t}$ is time, $\varepsilon$ is the strain, $\mathrm{E}_{1}$ and $\eta_{1}$ are the elastic and viscous constants of the spring and dashpot in series; $E_{2}$ and $\eta_{2}$ are the elastic and viscous constants of the spring and dashpot in parallel. The constants for the 4-parameter model were determined from the time-strain curve as Figure 2 shows, thus:

$$
\mathrm{E}_{1}=\frac{\sigma_{\mathrm{o}}}{\varepsilon_{\mathrm{o}}} \quad \text { and } \quad \eta_{1}=\frac{\sigma_{\mathrm{o}}}{\mathrm{m}}
$$

where $m$ is the slope of the viscous flow on the curve strain-time (see figure $2 b$ ). $E_{2}$ and $\eta_{2}$ were determined using the tool solver on an Excel spreadsheet. Through a response surface analysis, a correlation was made between microscopic flow and interactions between the solid phase and the thermoplastic. 


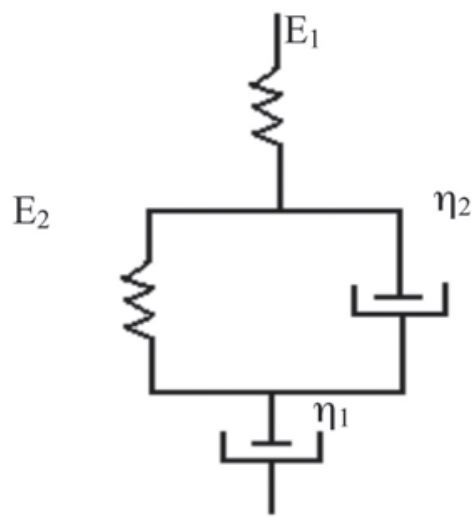

a)

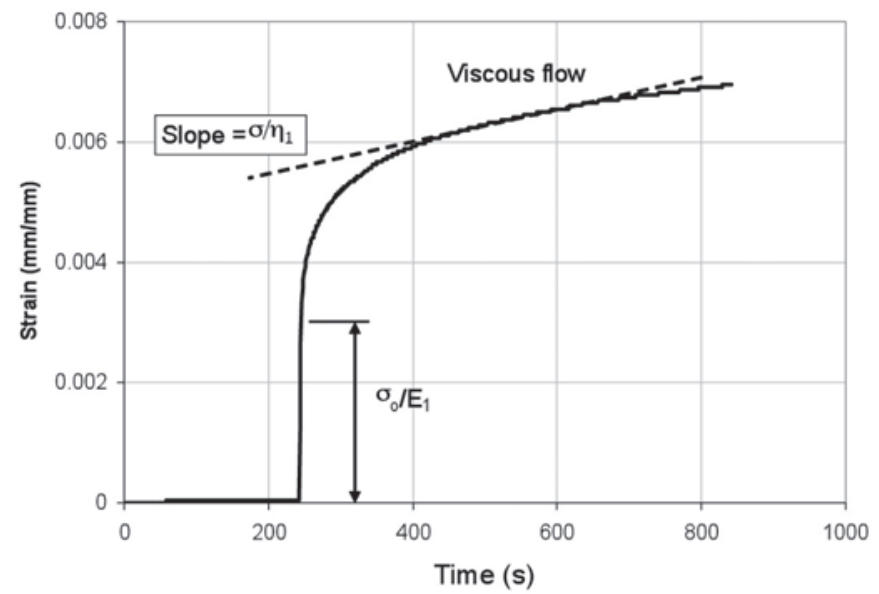

b)

Figure 2: $\quad$ a) Four-parameter model with Maxwell elements and Voigt element in series.

b) Response of the 4-parameter model to a constant applied stress.

Analogy model parameters to mechanical interlocking: The analogy presented by Rosen (1982) can be used to explain the mechanical interlocking mechanism between filler and the thermoplastic, thus:

Dashpot 1: represents the slippage between phases. This interfacial movement is responsible for unrecoverable viscous flow in the composite. The value of $\eta_{1}$ governs the equilibrium flow of the composite.

Spring 1: represents the initial elastic strain of the composite. The magnitude of this component is represented by the constant, $\mathrm{E}_{1}$.

Dashpot 2: represents the recoverable time-dependent strain resulting from the molecular motion of both phases during deformation.

Spring 2: represents the restorative force brought about by disruption of the chains and wood particles oriented by a stress to their most original random or highest entropy configuration.

Flaw probability and wood species: When wood cells collapse during processing, this produces an empty lumen that will cause increased void content of WPCs. In this study, the void content (in percentage based on the total AOI area) was determined for a large numbers of AOIs for each case. We observed that the stress at which WPCs made of different wood species fail, usually depends on the presence of flaws (voids) that may occur randomly across the transverse section of a WPC. When many voids are expected across the transverse section of the composites, variability in strength should also be expected (Hull and Clyne 1996). Statistical tools were used to explain the variability in properties of WPCs that may influence the future design of these materials. When a stress $\sigma$ is applied, the parameter " $n$ " defines the number of voids (of arbitrary size) per unit of area sufficient to cause failure under stress. Then, the Weibull distribution can be used to analyze the failure mechanisms on WPCs studied here (Bodig and Jayne1982). The probability of any given element failing depends on $n$ and on the probability of rupture 
or failure $\left(\mathrm{P}_{\mathrm{f}}\right)$. Then, the equation to predict the probability of failure of WPCs made of different wood species, assuming that all samples tested have practically the same volume (V), becomes (Askeland and Phulé 2004):

$$
\mathrm{P}_{\mathrm{f}}(\mathrm{V})=1-\exp \left[-\mathrm{V}_{\mathrm{C}}(\sigma / \mathrm{b})^{\mathrm{w}}\right]
$$

which is a two-parameter (b,w) Weibull distribution. $\sigma$ is the stress level at which the probability of failure is calculated; $\sigma_{\mathrm{o}}$ is the minimum possible ultimate stress for which the survival probability, $\mathrm{P}_{\mathrm{s}}$, is $\cong 0.37$ or $37 \%$; assuming brittle failure during the tensile test, $b$ takes a characteristic value which is the strength corresponding to the $63^{\text {rd }}$ percentile of the cumulative density function of $\sigma . V_{C}$ represents the void content into each WPC under longitudinal tensile stress. Taking the logarithm twice on Equation 6 we get:

$$
\ln \left[\ln \left(1 / \mathrm{P}_{\mathrm{s}}\right)\right]=\mathrm{w}(\ln \sigma-\ln \mathrm{b})-\ln \mathrm{V}_{\mathrm{C}}
$$

A plot, in this form, of the data for $\mathrm{P}_{\mathrm{s}}$ as a function of $\sigma$ should give a straight line with a gradient of $\mathrm{w}$ (Hull and Clyne 1996). Lastly, the Weibull modulus ( $w$ ) was estimated using the tensile data by fitting the data to Equation 7. Tensile strength values were arranged in an increasing order (for each WPC) assigning a numerical rank to each specimen, with the specimen having the lowest tensile strength assigned the value of 1 (Askeland and Phulé 2004). The total number of specimens is $n_{T}$. The probability of failure $P_{f}$ is then the numerical rank divided by $\left(\mathrm{n}_{\mathrm{T}}+1\right)$. Then $\ln \left[\ln \left(1 / \mathrm{P}_{\mathrm{s}}\right)\right]$ versus $\sigma$ was plotted and using simple linear regression analysis, the Weibull modulus was determined for each WPC.

\section{RESULTS AND DISCUSSION}

Different wood species were used to make WPC's of $40 \%$ wood content. Usually, the production of these composites involves higher ratios of natural fibers; but it was found in previous experiments that a lower percentage of wood facilitates the morphological study of the wood-thermoplastic interaction through SEM image analysis. Interrelationships between the wood species' anatomical characteristics and the mechanical properties of the final composite can be established. Anatomical features, determined in the first part of this research, explain the phase morphology and mechanical properties of experimental composites (Gacitúa and Wollcot). We found that void content is a significant factor affecting the performance of WPCs and the probability of failure under stress, and results from interactions between the anatomical features and the behavior of wood species during processing. Results showed that collapse of wood cells during extrusion impedes the free flow of the thermoplastic into the lumens and contributes to the void content measured with SEM on transverse sections of WPCs made of the three wood species. The cellular structure of wood particles may change through a local densification process (plastic deformation of the cell wall) and is affected by pressure, temperature, and time. One of the major factors influencing the mechanical and physical behavior of densified wood particles is the amount and type of cellular collapse. Cellular collapse occurs by either elastic buckling, plastic yielding, or brittle crushing, depending on the environmental conditions and the nature of the cell wall material (Wolcott 1989). The competing processes of fluid diffusion and cellular collapse, occurring during processing WPCs, must be considered in understanding the behavior of the two phases of the system. 
Latewood-earlywood proportion and mechanical properties: Figure 3 shows the latewood proportion for all wood species and locations, obtained from cross sections of the solid wood sections used to produce wood flour. According to these measurements, the earlywood volume is estimated at over $70 \%$ of the total volume of the wood species analyzed here. The method used can detect differences among wood species in terms of this macro-anatomical feature. There was a higher average earlywood proportion in lodgepole pine (corewood) and grand fir (outerwood), at 79\% and 77\% respectively. A lower earlywood proportion was determined for Douglas-fir (corewood) and lodgepole pine (outerwood), at $72 \%$ and $73 \%$ respectively. The earlywood proportion was used as an input to determine the relative interface area parameter in the first part of this research to construct empirical models for predicting mechanical properties.

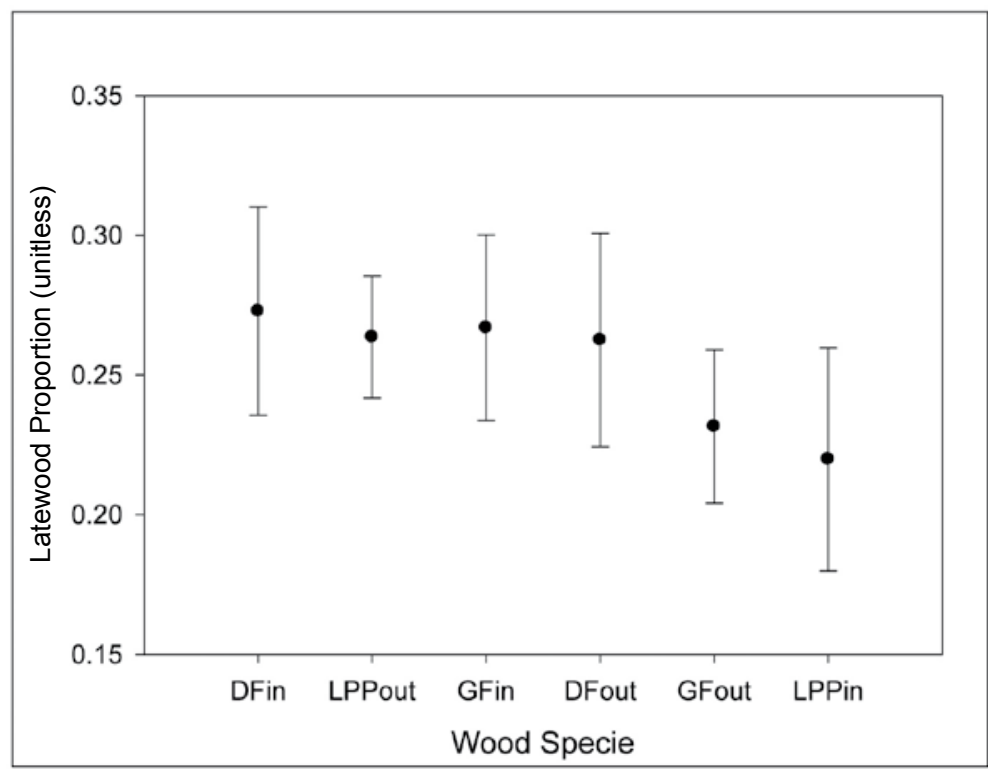

Figure 3: Latewood proportion for different wood species and locations into a log (DF: Douglas-fir, GF: grand fir, LPP: lodgepole pine and "in-out" are corewood and outerwood).

Figure 4 shows the effect of wood species and location on the flexure and tensile strength. There is no unique combination of wood species-location with higher mechanical properties, but significant differences were found in some cases in terms of modulus of elasticity (MOE) and modulus of rupture (MOR). In general, composites made of grand fir presented significantly higher MOE-MOR compared to the other wood species. Grand fir from outerwood performed better in the mechanical tests applied in this study. Initially, this can be explained in terms of the physical interaction of wood-HDPE parameters determined in the first part of this research. Grand fir from outerwood presented a high interfacial area parameter (Gacitua and Wolcott 2008) and lower potential for cell collapse under a vacuumpressure treatment at $200{ }^{\circ} \mathrm{C}$. The opposite extreme occurred for lodgepole pine composites. Again, considering the interaction parameter interfacial area, lodgepole pine from outerwood was the species with the lowest interfacial area, especially when earlywood was measured (being that the volume of earlywood was significantly higher than the latewood volume, in all cases). This interaction depends on anatomical features for this species (diameter and number of pits, cell wall thickness) that may impede the interlocking during cell collapse. This could explain the reduced mechanical properties determined for this composite. 
Douglas-fir presented an intermediate level of mechanical properties compared with the other wood species. Douglas-fir composites from outerwood had a lower MOE-MOR, for both flexure and tensile, than corewood. The area under the entire stress-strain diagram on Figures $4 \mathrm{a}$ and $4 \mathrm{~b}$ provides a measure of the composite's ability to absorb energy up to the point of fracture; this is called toughness. The greater the total area under a stress-strain diagram, the tougher the composite. According to this definition, the design of a tough WPC for a specific application and better performance would depend on the correct choice of the wood species to produce wood flour and finally the composite. Grand fir (outerwood) presented the higher toughness for flexure and tensile tests.

In terms of strength and modulus, the expected differences among species for the composites would become more significant as the weight fraction of wood flour increases. An increase in the weight fraction of the natural filler would increase the affect of the anatomical features of wood on phase interactions and mechanical properties.

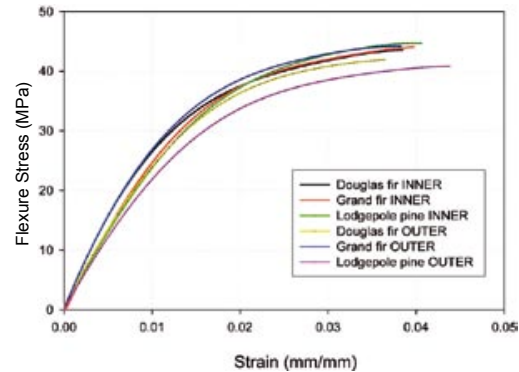

(a)

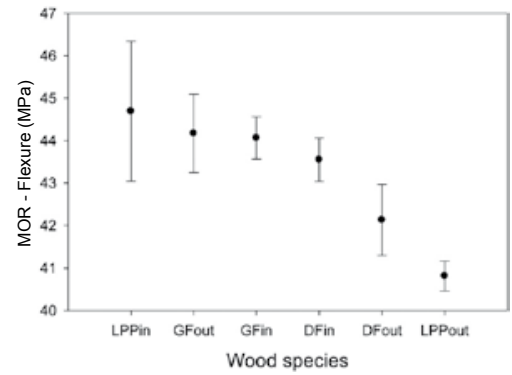

(c)

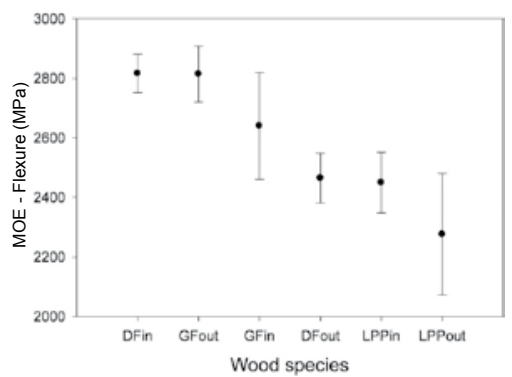

(e)

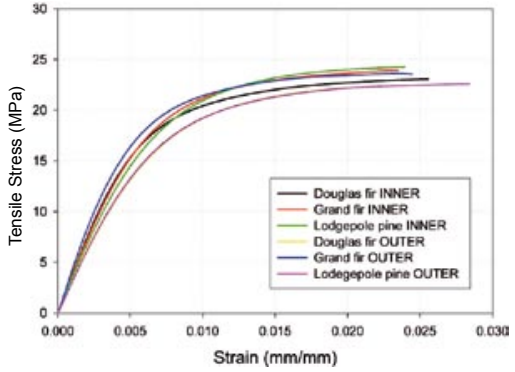

(b)

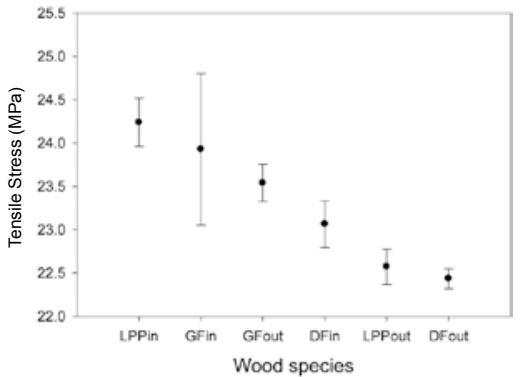

(d)

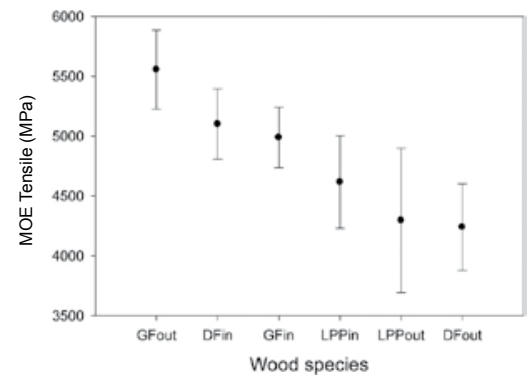

(f)

Figure 4: Wood-HDPE composites in flexure and tension: Stress-strain curves (a, b); MOR and tensile stress (c, d) and $\operatorname{MOE}(\mathrm{d}, \mathrm{f})$. Notation: out and outer is outerwood; in and inner is corewood; DF: Douglas-fir, GF: Grand fir, LPP: Lodgepole pine. 
Viscoelastic properties: Viscoelastic constants of the 4-parameter model can be used in an analogy to describe the interactions, at microscale, between phases of the composite under constant stress. One of these mechanisms is mechanical interlocking, due to the interpenetration of the molten thermoplastic into the wood cell structure during the extrusion and injection molding processes. It was discussed that the interpenetration was affected by the cell collapse. Cell collapse does not contribute to good stress transfer in a composite and could also affect the magnitude of the viscoelastic parameters.

Table 1 presents values of the 4-parameter viscoelastic constants. A higher resistance to strain was determined for grand fir composite outerwood and a lower resistance for lodgepole pine outerwood composites. Comparable results were presented by other researchers in terms of the parameter related to interfacial interactions, the viscous constant, $\eta_{1}$. Acha et al. (2007) reported a $\eta_{1}$ value of $9.91 \times 10^{12}$ $\mathrm{Pa} \times \mathrm{s}$ for composites made of $30 \%$ jute fabrics (by weight), polypropylene (PP) without additives and determined at room temperature. Nunez et al. (2004) calculated a $\eta_{1}$ parameter equal to $1.92 \times 10^{13} \mathrm{~Pa} \times \mathrm{S}$ for wood flour composites (Eucalyptus saligna), PP, copolymer maleic anhydride and PP and also determined at $20^{\circ} \mathrm{C}$. Values reported here for $\eta_{1}$ vary between $2.28 \times 10^{12}$ to $6.15 \times 10^{12} \mathrm{~Pa} \times \mathrm{s}$, depending on the wood species.

A higher interfacial area, already determined using a vacuum-bagging experiment and SEM analysis, could enhance mechanical interlocking between phases and ultimately affect the slips between phases responsible for flowing between the matrix and the natural filler. There was a significant difference for composites fabricated with different softwoods in terms of the equilibrium flow under a constant flexure stress.

Table 1: Viscoelastic constant for the 4-parameter model used on composites with different wood species.

\begin{tabular}{|l|c|c|c|c|}
\hline Wood species - location & $\begin{array}{c}\text { Dashpot 1, } \eta_{1} \\
\mathrm{~Pa} \times \mathrm{s} \times 10^{12}\end{array}$ & $\begin{array}{c}\text { Spring 1, } \mathrm{E}_{1} \\
\mathrm{~Pa} \times 10^{6}\end{array}$ & $\begin{array}{c}\text { Dashpot 2, } \eta_{2} \\
\mathrm{~Pa} \times \mathrm{s} \times 10^{11}\end{array}$ & $\begin{array}{c}\text { Spring 2, } \mathrm{E}_{2} \\
\mathrm{~Pa} \times 10^{6}\end{array}$ \\
\hline Grand fir, outerwood & 6.1484 & 15.07 & 1.3933 & 33.28 \\
\hline Douglas-fir, corewood & 4.4807 & 14.31 & 1.2107 & 30.39 \\
\hline Grand fir, corewood & 4.1849 & 14.03 & 1.2475 & 27.00 \\
\hline Lodgepole pine, corewood & 3.4064 & 14.06 & 1.0837 & 27.13 \\
\hline Douglas-fir, outerwood & 3.1718 & 14.14 & 1.0936 & 23.40 \\
\hline Lodgepole pine, outerwood & 2.2814 & 11.96 & 1.0898 & 2 \\
\hline
\end{tabular}

As Table 1 presents, the decrease in magnitude for each viscoelastic constant is consistent with mechanical properties of composites from different combinations of wood-location. Of particular interest is the constant that could be related with slippage between phases, $\eta_{1}$. An increasing elongational viscosity of the Maxwell Dashpot, $\eta_{1}$, results in a decrease in the slope of the viscous flow portion of the strain-time curve. As shown in Figure 5a, the ranking of $\eta_{1}$ and the associated interface interaction was consistent to the descending ranking obtained for mechanical properties like tensile, flexure and toughness. Figure $5 \mathrm{~b}$ shows the comparison between predicted strain at a certain time and the experimental strain. 


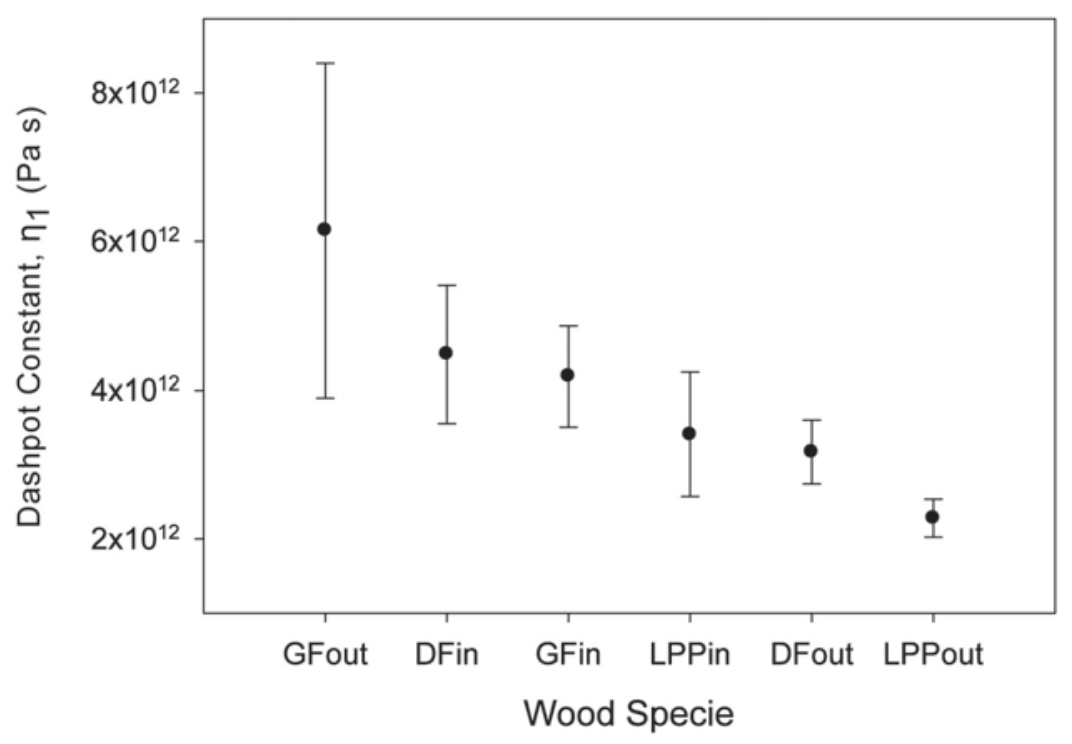

(a)

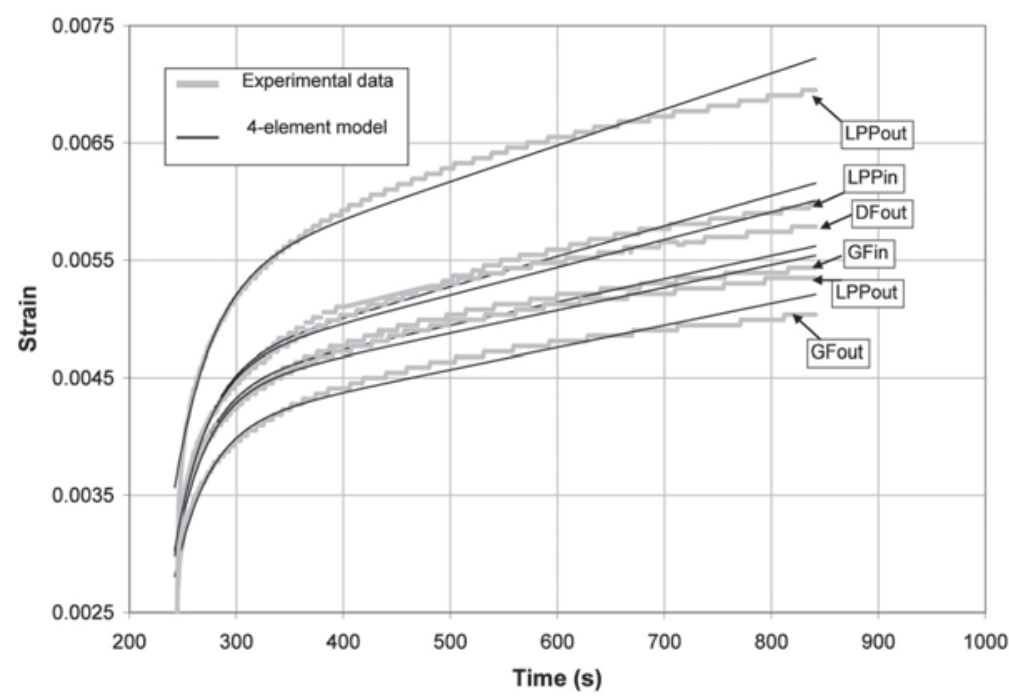

(b)

Figure 5: (a) 95\% interval of confidence for the calculated elongational viscosities for experimental WPCs. (b) DF: Douglas-fir, GF: Grand fir, LPP: Lodgepole pine. Corewood (in) and outerwood (out). Creep response of experimental WPCs made with injection molding. Comparison experimental vs. 4-element model.

SEM morphology analysis: The selection of specific AOIs in a symmetric cross section of wood composites allowed a very precise micro-description of filler and thermoplastic phase. Through this analysis it was possible to identify and quantify the number and area of voids as their probable source associated to processing conditions and wood morphology. Figure 6 shows the average void content determined from AOIs of wood composites fabricated of different wood species. Figure 7 shows a characteristic result for the image analysis process designed to measure the void content. In general, the decreasing order of void content on composites made of wood flour particles was:

\section{Grand fir $<$ Douglas-fir $<$ Lodgepole pine}


In all cases the void content was lower than 2.5\%. According to Agarwal and Broutman, a good composite should have less than $1 \%$ of voids, whereas a poorly made composite has up to a $5 \%$ void content. Voids are formed between the fiber and matrix which can cause a pull-out effect. A higher mechanical interlocking can increase the interfacial frictional sliding. This process can absorb significant quantities of energy and can affect the modulus and toughness of the WPC. Another void source observed was due to cell collapse and the small spaces in the lumen after plastic deformation during extrusion. A poor interpenetration of the molten thermoplastic into lumens generates conditions for a free buckling of the cell wall during extrusion. WPCs made of Grand fir and Douglas-fir have an average void content lower than $1 \%$. In composite science, higher void contents usually mean lower fatigue resistance, greater susceptibility to water penetration and weathering, and increasing variation or scatter in strength properties (Agarwal and Broutman 1990, Askeland and Phule 2004).

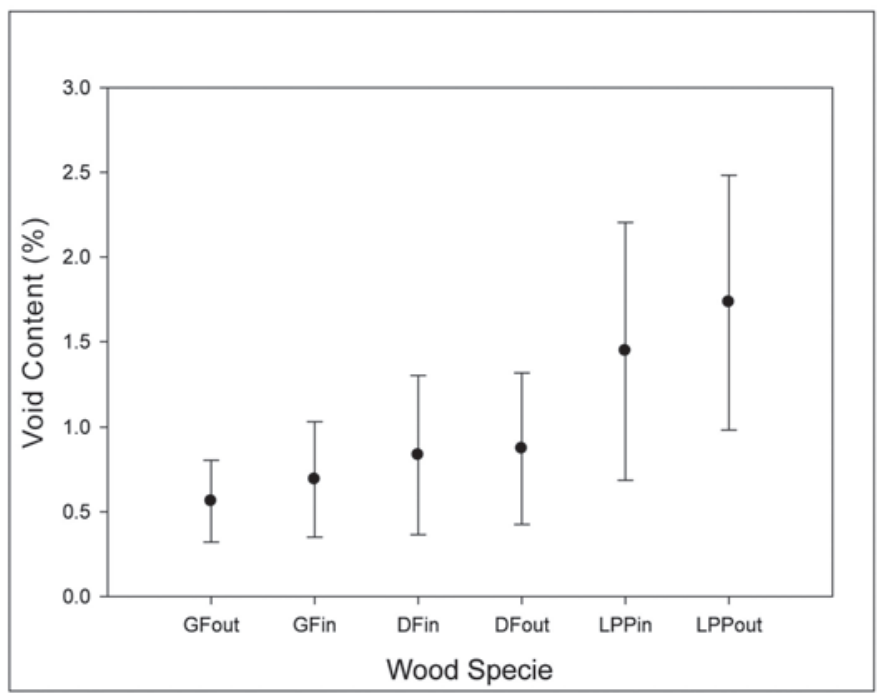

Figure 6: The 95\% interval of confidence for mean void content of WPC with different wood species. DF: Douglas-fir, GF: Grand fir, LPP: Lodgepole pine corewood (in) and outerwood (out).
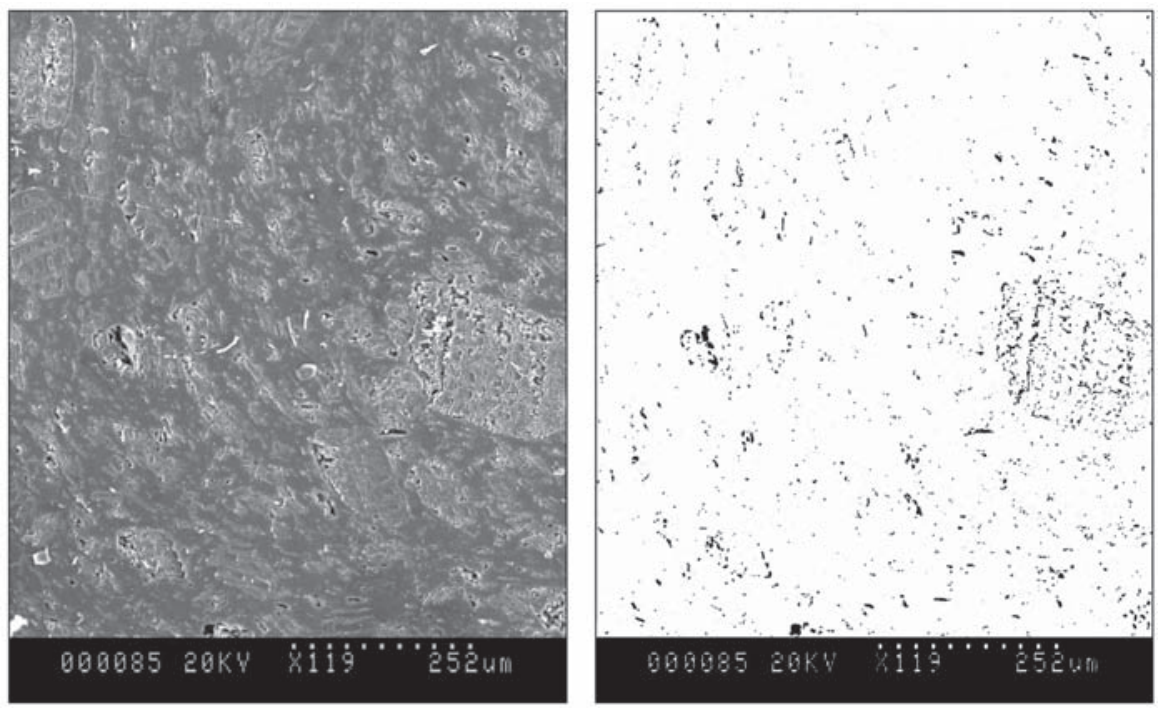

Figure 7: An example of a SEM picture and subsequent image treatment to determine void content. Composite made with Lodgepole pine wood flour (outerwood). 
Prediction of failure under tensile stress: This study found an important number of inhomogeneities, or voids, in experimental WPCs. This feature may reduce the mechanical properties because voids do not transmit stresses and can cause stress concentration. Statistical tools such as the Weibull distribution were used to ensure reliability of the data, to address variability in properties of WPCs, and to avoid premature failures. Table 2 presents the estimated Weibull modulus using Equation 7. The larger the slope or w value, the more uniform the composite. This statement is supported by the lower variability of tensile strength for composites made of Douglas-fir (outer area) shown in Figure 4d. The characteristic strength for composites prepared using Lodgepole pine (corewood) was also higher (24.24 MPa), suggesting that a smaller average void size area $\left(13.5 \mu \mathrm{m}^{2}\right)$ may not lead to fracture easily. The Weibull parameter for the void area distribution for this composite was on the upper level, which represents a more uniform flaw distribution. Data on survival probability (log scale) and tensile strength resulted in a straight line when plotted. The slope of this line provides a measure of the variability (i.e. the Weibull modulus). Figure 8 shows an example of the probability of survival of WPCs prepared with material from the outerwood of different wood species. For composites of Douglas-fir (outerwood), the regression line is almost vertical (high w value); this means that there is a small variation in the tensile strength. On the other hand, composites made of Grand fir (outerwood) presented a high tensile strength but a high variability $(\mathrm{w}=4.8)$. Good reliability in design could be obtained for WPC with a high w value. The WPCs studied here have the same family of flaws or defects, mainly voids (due to cell collapse and subsequent empty cells), resulting in a Weibull modulus between 1 to 10 ; this means there is significant effect of the selected wood species in the strength and reliability of WPCs.

Table 2: Weibull modulus and Weibull parameter for tensile strength and void content, respectively.

\begin{tabular}{|c|c|c|c|c|c|}
\hline \multirow{2}{*}{ Composite } & \multicolumn{2}{|c|}{$\begin{array}{l}\text { Weibull modulus } \\
\text { Tensile strength }\end{array}$} & \multirow{2}{*}{ Composite } & \multicolumn{2}{|c|}{$\begin{array}{l}\text { Weibull parameter } \\
\text { Void content }\end{array}$} \\
\hline & $\begin{array}{c}\mathrm{w} \text { and } \\
\text { correlation } \\
\text { coefficient }\end{array}$ & $\begin{array}{l}\text { Average tensile } \\
\text { strength (MPa) }\end{array}$ & & W & $\begin{array}{c}\text { Average } \\
\text { void area } \\
\left(\mu \mathrm{m}^{2}\right)\end{array}$ \\
\hline Grand fir, corewood & $1.1126(\mathrm{r}=0.88)$ & 23.93 & Lodgepole pine, corewood & 1.1646 & 13.50 \\
\hline Lodgepole pine, corewood & $3.555(\mathrm{r}=0.89)$ & 24.24 & Grand fir, outerwood & 1.1591 & 14.68 \\
\hline Douglas-fir, corewood & $3.7651(\mathrm{r}=0.92)$ & 23.07 & Douglas-fir, outerwood & 1.1686 & 14.75 \\
\hline Grand fir, outerwood & $4.8389(\mathrm{r}=0.93)$ & 23.54 & Lodgepole pine, outerwood & 1.1204 & 15.20 \\
\hline Lodgepole pine, outerwood & $5.3787(\mathrm{r}=0.99)$ & 22.57 & Grand fir, corewood & 1.0868 & 15.76 \\
\hline Douglas-fir, outerwood & $9.4794(\mathrm{r}=0.99)$ & 22.44 & Douglas-fir, corewood & 1.0499 & 15.81 \\
\hline
\end{tabular}




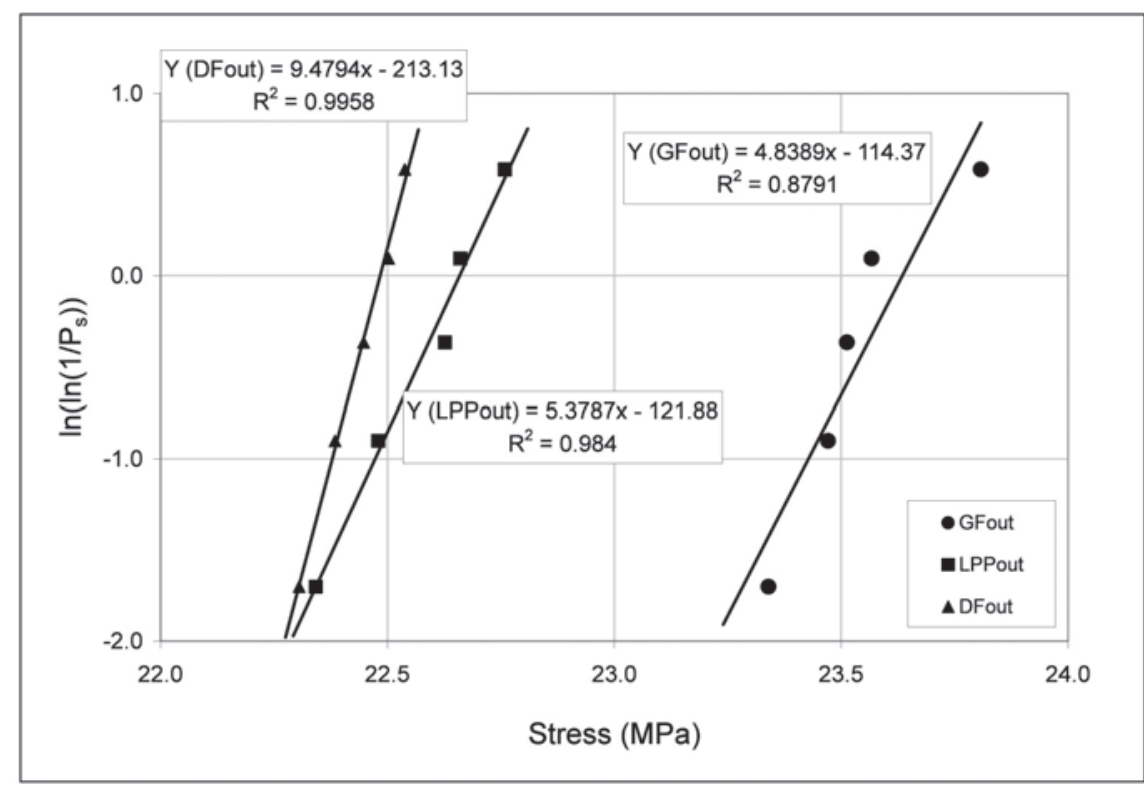

Figure 8: Survival probability of composites under tensile stress. WPC produced of three wood species from outerwood.

Macroscopic features of wood species affecting mechanical properties: It was demonstrated that anatomical features such as open pits, as well as their number and distribution, are directly related to the potential flow area of molten HDPE into the wood cell structure, causing mechanical interlocking and eventually enhancing properties including modulus, toughness and strength (Gacitua and Wolcott 2008). Wood species presenting a high interfacial area have the potential for better mechanical interlocking reflected on the viscous constant of the Maxwell model (Dashpot 1). Equation 9 represents a response surface of the tensile modulus of elasticity versus $\eta_{1}$ and the relative interfacial area $\left(A_{R}\right)$. The relative interfacial area for each wood species-location, was determined by Gacitua and Wolcott (2008), as:

$$
\mathrm{A}_{\mathrm{R}}=\mathrm{A}_{\mathrm{EW}} e_{w}+\mathrm{A}_{\mathrm{LW}} l_{w}
$$

where $\mathrm{A}_{\mathrm{EW}}$ and $\mathrm{A}_{\mathrm{LW}}$ are the mean interfacial area for latewood and earlywood, respectively. These areas of interaction were determined with a vacuum bagging experiment (Gacitua and Wolcott 2008). The relative interfacial area is a representative parameter of wood used as raw material to produce wood flour and the composite. This relative parameter was used for correlations, considering different responses of earlywood and latewood in a specific wood-thermoplastic interaction process. Macroscopic features (earlywood-latewood) for all wood species-locations, IFA and mechanical properties, were considered in a multiple regression analysis.

Based on the polynomial regression analysis for factors $\eta_{1}$ - relative IFA and the response variable, $\mathrm{MOE}$ in tensile and flexure, good correlation coefficients were obtained in both cases $(r=0.96)$ and according to the equation:

$$
\mathrm{MOE}=725+0.547 \mathrm{~A}_{\mathrm{R}}+0.0035 \eta_{1}(\mathrm{MPa})
$$




\section{CONCLUSIONS}

Anatomical features may explain the phase morphology and mechanical properties of WPCs made without additives. An interphase factor affecting the mechanical properties and toughness of WPC is the slippage between phases determined using a viscoelastic model and its parameters as an analogy. The higher the viscous flow parameter $\left(\eta_{1}\right)$, the lower is the deformation of the WPC under constant stress. The increase of the $\eta_{1}$ constant (phase friction slip) is facilitated by a higher interpenetration and interface area between wood particles and HDPE. Composites made of grand fir outerwood produced a higher $\eta_{1}$ value, which agrees with mechanical properties and toughness of experimental WPC. Another associated factor contributing to the final strength and variability of WPCs is the void content. A poor interpenetration of the molted thermoplastic into the cell lumens generates conditions for the free buckling of cell walls during extrusion, which finally results in an important source of void generation. According to the Weibull distribution analysis for void content, there is a significant effect of the selected wood species in the strength and reliability of the final wood composite. High correlation coefficients were determined for multiple regression models used to predict mechanical properties of experimental WPCs based on the slippage between phases and the interfacial area determined in previous experiments.

\section{REFERENCES}

Acha, B.; Reboredo, M.; Marcovich, N. 2007. Creep and dynamic mechanical behavior of PP-jute composites: Effect of the interfacial adhesión. Composites part A 38: 1507-1516.

Agarwal, B.D.; Broutman, L.J. 1990. Analysis and performance of fiber composites. John Wiley \& Sons, Inc. 449 p. USA.

Askeland, D.R.; Phule, P.P. 2004. Essentials of materials science and engineering. Thomson Canada Limited. 588 p. USA.

American Society for Testing and Materials. 2007. Test method for tensile properties of plastics. ASTM D 638-03

American Society for Testing and Materials. 2007. Test methods for flexural properties of unreinforced and reinforced plastics and insulating materials. ASTM D 790-03

Bodig, J.; Jayne, B.A. 1982. Mechanics of wood and wood composites. Van Nostrand Reinhold Inc. 712 p. USA.

Gacitua, W.; Wolcott, M.P. 2008. Morphology of wood species affecting wood-plastic interaction. Ph.D. dissertation, Civil Enginering Department, Washington State university. Pullman WA - USA.

Hull, D.; Clyne, T.W. 1996. An introduction to composites materials. Cambridge solid state science series. 326 p. USA.

Houshyar, S.; Shanks, R.A.; Hodzic, A. 2005. Tensile creep behaviour of polypropylene fibre reinforced polypropylene composites. Polymer Testing 24:257-264. 
Nunez, A.; Marcovich, N.; Aranguren, M. 2004. Analysis of the creep behavior of polypropylenewoodflour composites. Polymers Engineering and Science 44 (8): 1594-1603.

Omena-Pina, S.R.; Pardini, L.C.; Pionino-Neto, F. 2004. Weibull modulus of bi-directional carbon fibre reinforced carbon composites. Centro Técnico Aeroespacial Instituto de Aeronautica e Espaco. Divisao de Materiais - AMR 12228-904- Sao Jose dos Campos - SP- Brazil.

Packman, D.E. 2003. Surface energy, surface topography and adhesion. International Journal of Adhesion \& Adhesives 23:437-448.

Rosen, S.L. 1982. Fundamentals principles of polymeric materials, section 18.3. John Wiley \& Sons. 883 p. USA.

Stark, N. 1997. Effect of Species and Particle Size on Properties of Wood-Flour-Filled Polypropylene Composites. Intertech conferences, Functional fillers for thermoplastics and thermosets.

Throne, J.L. 1988. Creep and stress relaxation, section 7. Engineering plastics, Vol. 2 Engineered Materials Handbook, ASTM International.

Wolcott, M.P. 1989. Modeling viscoelastic cellular materials for the pressing of wood composites. $\mathrm{PhD}$ Dissertation. VPI\&SU, Blacksburg, VA.

Wolcott M. P. 2003. Mechanical interlocking in wood-plastic composites: southern yellow pine vs Douglas-fir filler. Internal report, Wood material and engineering laboratory, Washington State University Pullman, WA. 
